Supporting Information

\title{
Radioluminescent Ionic Liquids: Designer Materials for Detecting and Quantifying Ionizing Radiation
}

Dario Rodrigues, $,{ }^{\dagger},, \sharp$ Gabriela P. Sarmiento ${ }^{\dagger}$ Nicolas I. Krimer,${ }^{\dagger}$ and Martin Mirenda ${ }^{*}, \dagger$

†Gerencia Química, Centro Atómico Constituyentes, Comisión Nacional de Energía Atómica

(CNEA-CONICET), Av. Gral. Paz 1499, B1650KNA San Martín, Buenos Aires, Argentina.

Departamento de Física, Facultad de Ciencias Exactas y Naturales, Universidad de Buenos

Aires, Ciudad Universitaria, Pab. I, C1428EHA, Buenos Aires, Argentina.

*E-mail: dariorodrigues@cnea.gov.ar; mirenda@cnea.gov.ar

\section{Absorption and fluorescence spectra of $\left[\mathrm{BMIm}^{+}\right]_{2}\left[\mathrm{Cl}^{-}\right]\left[\mathrm{Tos}^{-}\right]$and $\left[\mathrm{H}^{+}\right]\left[\mathrm{Tos}^{-}\right]$aqueous solutions}

The absorption spectra of $\left[\mathrm{BMIm}^{+}\right]_{2}\left[\mathrm{Cl}^{-}\right]\left[\mathrm{Tos}^{-}\right]$and two different aqueous solutions of $\left[\mathrm{H}^{+}\right]\left[\mathrm{Tos}^{-}\right]$are presented in Figure S1a. A slightly redshift is observed as the ionic strength increases. The conserved shape of the vibronic structure indicates that no ground state aggregates are formed. Besides, a clear excimer emission is observed in Figure $\mathrm{S} 1 \mathrm{~b}$ for the $2 \mathrm{M}$ aqueous solution of $\left[\mathrm{H}^{+}\right]\left[\mathrm{Tos}^{-}\right]$. The shape of the fluorescence spectrum of $\left[\mathrm{BMIm}^{+}\right]_{2}\left[\mathrm{Cl}^{-}\right]\left[\mathrm{Tos}^{-}\right]$agrees with those of the monomeric species obtained in a $2 \mathrm{mM}$ aqueous solution of $\left[\mathrm{H}^{+}\right]\left[\mathrm{Tos}^{-}\right]$ confirming that, despite the high fluorophore concentration of $\sim 2 \mathrm{M}$ in the IL, no excited state aggregates are formed. 

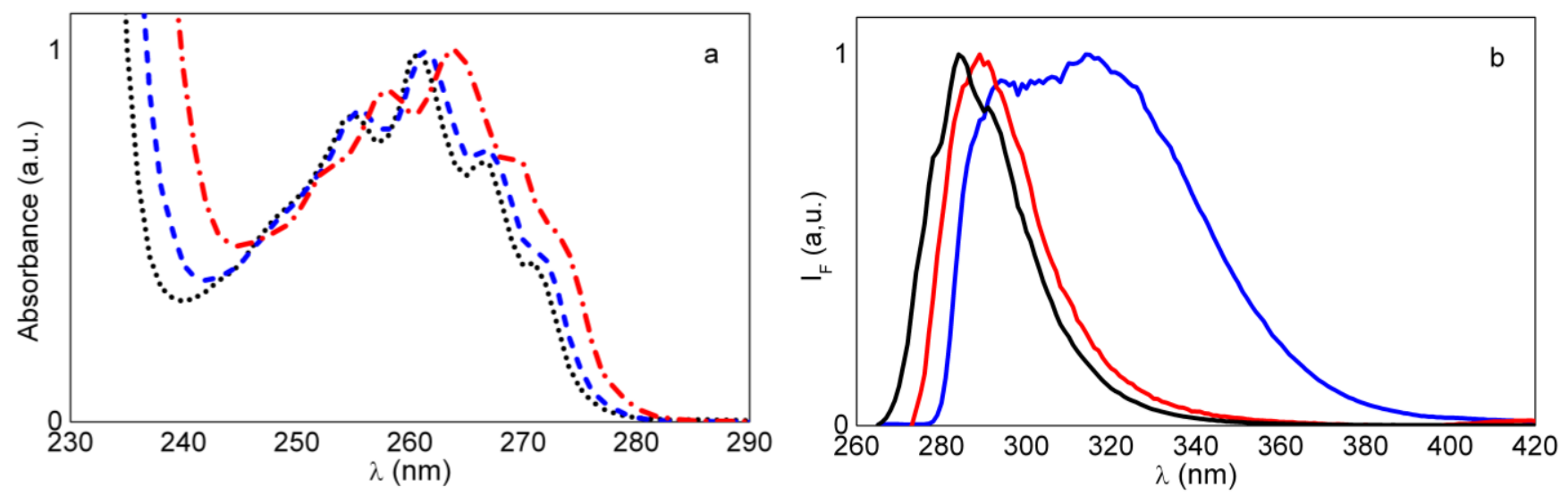

Figure S1. Normalized absorption (a) and fluorescence (b) spectra of a $2 \mathrm{mM}$ aqueous solution of $\left[\mathrm{H}^{+}\right]\left[\mathrm{Tos}^{-}\right]$(dotted and solid black lines), 2M aqueous solution of $\left[\mathrm{H}^{+}\right]\left[\mathrm{Tos}^{-}\right]$(dashed and solid blue lines), and $\left[\mathrm{BMIm}^{+}\right]_{2}\left[\mathrm{Cl}^{-}\right]\left[\mathrm{Tos}^{-}\right]$(dashed-dotted and solid red lines).

\section{Theoretical approach for the temperature dependence of fluorescence and radioluminescence}

The decrease of [Tos ${ }^{-}$] fluorescence with temperature can be described in terms of kinetic rateconstants, by the following equation: ${ }^{[1]}$

$$
\frac{1}{\Phi_{\mathrm{F}}(\mathrm{T})}=\frac{k_{\mathrm{F}}+k_{\mathrm{nr}}^{\prime 0}+k_{\mathrm{nr}}^{\prime} \cdot \mathrm{e}^{\frac{-\mathrm{W}_{\mathrm{I}}}{\mathrm{RT}}}}{k_{\mathrm{F}}}=\mathrm{A}+\mathrm{B} \cdot \mathrm{e}^{\frac{-\mathrm{W}_{\mathrm{I}}}{\mathrm{RT}}}
$$

where $\Phi_{\mathrm{F}}$ is the fluorescence quantum yield, $\mathrm{W}_{\mathrm{I}}$ is the activation energy, $k_{\mathrm{F}}$ is the radiative rateconstant, and $k_{\mathrm{nr}}^{\prime 0}$ and $k_{\mathrm{nr}}^{\prime}$ are the temperature-independent and dependent components of the non-radiative rate constant, respectively.

The number of photons emitted by a sample, $m$, is proportional to the number of excited states $\mathrm{N}_{\mathrm{Ex}}$ and $\Phi_{\mathrm{F}}$ through a geometrical constant $\mathrm{K}$ :

$$
\mathrm{m}=\mathrm{K} \cdot \Phi_{\mathrm{F}}(\mathrm{T}) \cdot \mathrm{N}_{\mathrm{Ex}}
$$

For alpha particles, $\mathrm{N}_{\mathrm{Ex}}=$ cte for the reasons stated in the main text of the work. Then, combining Equation 2, S1 and S2 it is obtained:

$\varepsilon_{\alpha}(\mathrm{T})=\left[1-e^{-\frac{v^{\prime}}{\mathrm{A}+\mathrm{B}^{\mathrm{W}_{\mathrm{i}} / \mathrm{RT}}}}\right]^{2}$ 
that describes the efficiency of the double temporal coincidences as a function of temperature employing four fitting parameters, namely: $\mathrm{A}, \mathrm{B}, \mathrm{W}_{\mathrm{I}}$ and $\mathrm{v}^{\prime}$.

For beta particles, $\mathrm{N}_{\mathrm{Ex}}$ is roughly proportional to the energy through the Birk's constant, $\mathrm{K}_{\mathrm{B}}$, according to:

$$
\mathrm{N}_{\mathrm{Ex}}=\mathrm{K}_{\mathrm{B}} \cdot \mathrm{E}^{\prime}
$$

Combining Equation 3, S1 and S4 it is obtained:

$$
\varepsilon_{\beta+C h}(\mathrm{~T})=\int_{0}^{\mathrm{E}} \mathrm{N}\left(\mathrm{E}^{\prime}\right) \cdot\left(1-\mathrm{e}^{-\left[\frac{\mathrm{v}^{\prime \prime} \cdot \mathrm{E}^{\prime}}{\mathrm{A}+\mathrm{Be}^{-\mathrm{W}_{\mathrm{i}} / \mathrm{RT}}+v^{\prime \prime \prime} \cdot \mathrm{k}\left(\mathrm{E}^{\prime}\right)}\right]}\right)^{2} \mathrm{d \textrm {E } ^ { \prime }}
$$

were $\mathrm{k}\left(\mathrm{E}^{\prime}\right)$ it the number of Cherenkov photons, ${ }^{[2]}$ and can be obtained by integration of the following expression $\mathrm{dk} / \mathrm{dx}=2 \pi \alpha\left(1 / \lambda_{1}-1 / \lambda_{2}\right)\left(1-1 / \mathrm{n}_{2} \beta_{2}\right)$ where $\mathrm{x}$ represents the length traveled by the electrons and $\beta_{2}=\left(\mathrm{W}_{2}-1\right) / \mathrm{W}_{2}$ with $\mathrm{W}=\mathrm{E} / \mathrm{m}_{0} \mathrm{c}^{2}+1$, being $\lambda_{1}$ and $\lambda_{2}$ the lower and upper limit of the wavelength region and $\alpha$ the fine structure constant. Based on this description, [Tos ${ }^{-}$] fluorescence intensity data and ${ }^{32} \mathrm{P}$ and ${ }^{241} \mathrm{Am}$ efficiency values were simultaneous fitted as a function of temperature by using Equations S1, S3 and S5 sharing A, B and $\mathrm{W}_{\text {I }}$ parameters. The resulting curves presented in Figure $3 b$ and $3 d$, satisfactory describes the observed trends. The fitted parameters with its uncertainties are given in Table S1.

Table S1. Fitted parameters describing the temperature behavior of $\left[\mathrm{Tos}^{-}\right]$fluorescence and the RadIL radioluminescence through Equations S1, S3 and S5. 


\begin{tabular}{ccc}
\hline Parameter & Value & Uncertainty \\
\hline $\mathrm{A}$ & 6.68 & 1.04 \\
$\mathrm{~B}$ & 7179 & 3222 \\
$\mathrm{~W}_{\mathrm{I}}[\mathrm{kJ} / \mathrm{mol}]$ & 15.43 & 1.29 \\
$v^{\prime}$ & 18.655 & 0.609 \\
$v^{\prime \prime}$ & 20.27 & 1.03 \\
$v^{\prime \prime \prime}$ & $1.115 \times 10^{-5}$ & $0.029 \times 10^{-5}$ \\
\hline
\end{tabular}

\section{Refraction index measurements}

The refractive indexes of the RadIL at different temperatures were measured at $589.3 \mathrm{~nm}$ in a thermostated Abbemat 300 TM automatic refractometer (Anton Paar). The values obtained are listed in Table S2. Cherenkov threshold is affected in less than 3\% in this temperature range due to the changes in the refraction index. As such, a negligible effect on the number of Cherenkov photons produced by high energy beta emitters as ${ }^{32} \mathrm{P}$ is expected, becoming imperceptible on the detection efficiency.

Table S2. Refraction index of RadIL at different temperatures.

\begin{tabular}{|c|c|c|c|}
\hline $\mathrm{T} /{ }^{\circ} \mathrm{C}$ & $\mathrm{nD}$ & $\mathrm{T} /{ }^{\circ} \mathrm{C}$ & $\mathrm{nD}$ \\
\hline 10 & $1.533(1)$ & 50 & $1.522(1)$ \\
\hline 15 & $1.532(1)$ & 55 & $1.520(1)$ \\
\hline 20 & $1.530(1)$ & 60 & $1.519(1)$ \\
\hline 25 & $1.529(1)$ & 65 & $1.518(1)$ \\
\hline 30 & $1.527(1)$ & 70 & $1.516(1)$ \\
\hline 35 & $1.526(1)$ & 75 & $1.515(1)$ \\
\hline 40 & $1.525(1)$ & 80 & $1.514(1)$ \\
\hline 45 & $1.523(1)$ & 85 & $1.513(1)$ \\
\hline
\end{tabular}




\section{Standardized radioactive aqueous solutions}

Table S3 summarizes the activity of the standardized radioactive aqueous solutions used in scintillation experiments.

Table S3. Activity of standardized radioactive aqueous solutions

\begin{tabular}{|c|c|c|c|}
\hline Radionuclide & Activity Concentration* $(\mathrm{kBq} / \mathrm{g})$ & mass $(\mathrm{mg})$ & Activity (kBq) \\
\hline${ }^{14} \mathrm{C}$ & $973(10)$ & $13.27(4)$ & $12.91(4)$ \\
\hline${ }^{241} \mathrm{Am}$ & $481(5)$ & $33.65(4)$ & $16.19(2)$ \\
\hline${ }^{32} \mathrm{P}$ & $829(8)$ & $10.19(4)$ & $8.45(3)$ \\
\hline
\end{tabular}

* referenced at the time of measurement

\section{Differential Scanning Calorimetry (DSC) and Thermal Gravimetry Analysis (TGA)}

Figures S2 and S3 show the DSC and TGA results for RadIL and $\left[\mathrm{BMIm}^{+}\right]_{2}\left[\mathrm{Cl}^{-}\right]\left[\mathrm{Tos}^{-}\right]$, respectively. Similar trends are observed for the two compounds, as expected, indicating that the low amount of $\left[\mathrm{HPTS}^{-3}\right]$ present in RadIL has no appreciable influence on the thermal properties compared to $\left[\mathrm{BMIm}^{+}\right]_{2}\left[\mathrm{Cl}^{-}\right]\left[\mathrm{Tos}^{-}\right]$. The endothermic peak above $200{ }^{\circ} \mathrm{C}$ is assigned to the thermal decomposition of $\left[\mathrm{BMIm}^{+}\right] \cdot{ }^{[3]}$ It is observed an endothermic broadband between 25 and $170{ }^{\circ} \mathrm{C}$, which is associated with the melting of the samples. A significant loss of mass takes place during this process, probably due to the water removing because the samples are very hygroscopic with a naked eye. Although the exposure of samples to ambient conditions was extremely limited, no experiments were performed in a controlled atmosphere because it is intended to obtain the thermal properties under the conditions of use of these materials. As such, the visual observation of the systems indicates that the two samples are liquid in the entire 
temperature range of interest. However, the results obtained in the thermal experiments cannot be determined whether they are supercooled liquids or they are mixtures with broad melting points influenced by the amount of hygroscopic water present. In any case, the experiments point out how difficult is to accurately determine some physicochemical parameters in ILs.
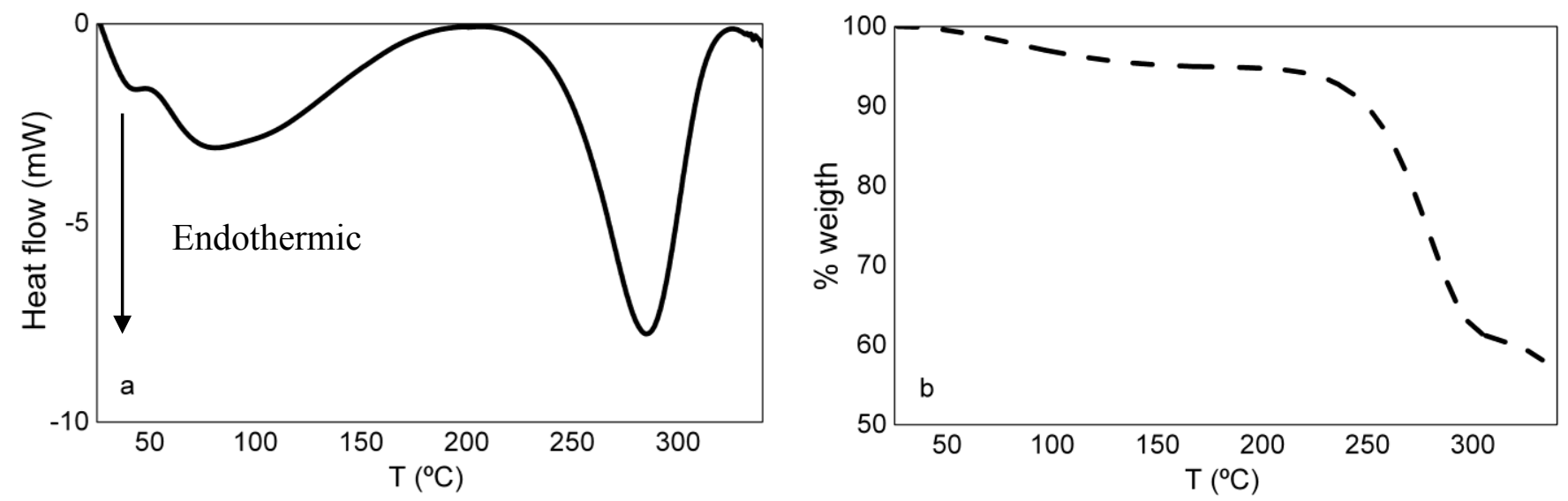

Figure S2. a) DSC and b) TGA of RadI..
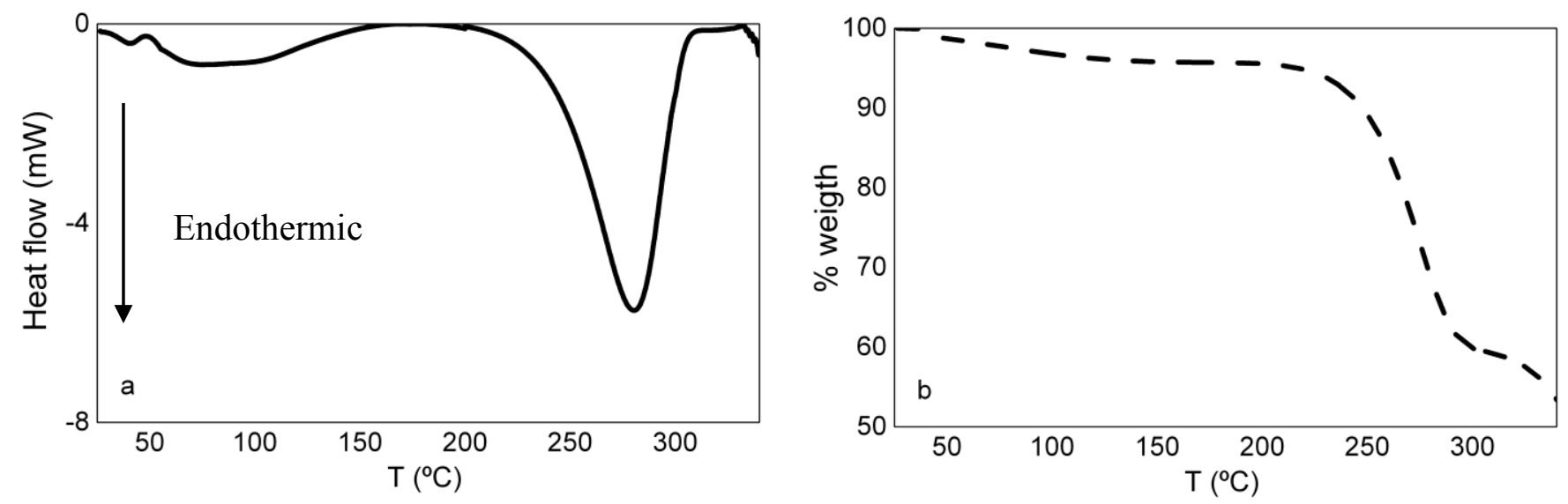

Figure S3. a) DSC and b) TGA of $\left[\mathrm{BMIm}^{+}\right]_{2}\left[\mathrm{Cl}^{-}\right]\left[\mathrm{Tos}^{-}\right]$. 
Figures S4 shows the DSC and TGA results for $\left[\mathrm{BMIm}^{+}\right]\left[\mathrm{Tos}^{-}\right]$. The thermal decomposition of the sample starts above $200{ }^{\circ} \mathrm{C}$. A clear endothermic peak at $63.9^{\circ} \mathrm{C}$ is observed, associated with the melting point of the sample. A water content of $\sim 0.5 \%$, estimated from TGA data, explains the lower value obtained for this melting point compared with those expected for the totally dried compound of $69.0^{\circ} \mathrm{C} .{ }^{[4]}$
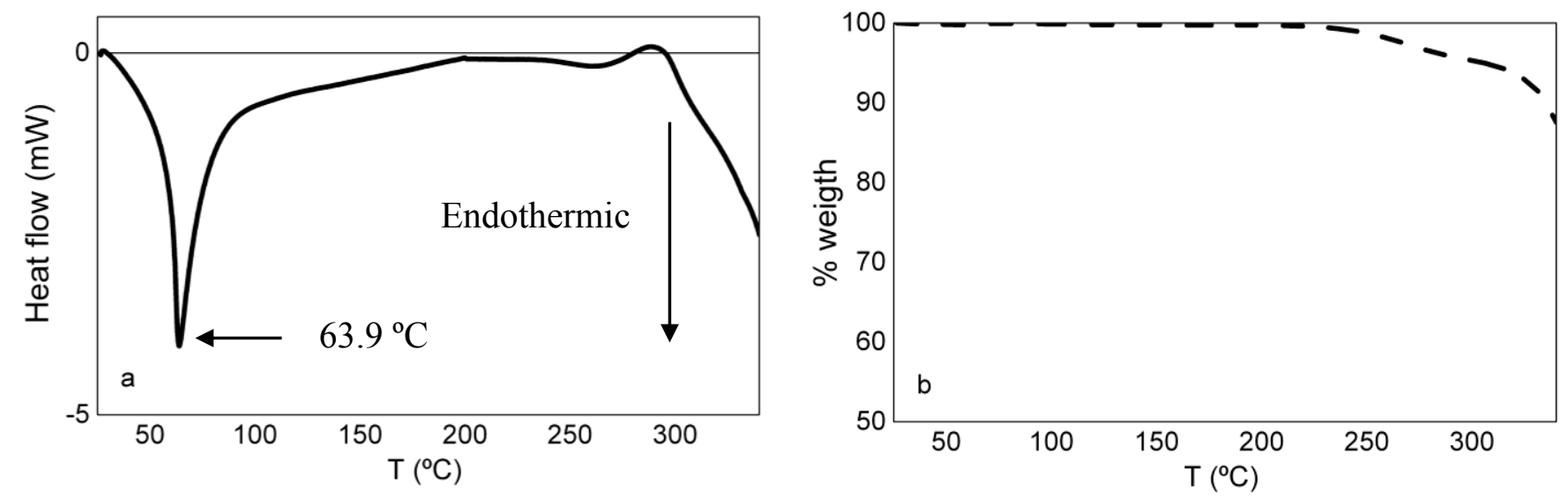

Figure S4. a) DSC and b) TGA of $\left[\mathrm{BMIm}^{+}\right]\left[\mathrm{Tos}^{-}\right]$.

Figures S5 shows the DSC and TGA results for $\left[\mathrm{BMIm}^{+}\right]\left[\mathrm{HPTS}^{-3}\right]$ The endothermic peak observed at $136.3{ }^{\circ} \mathrm{C}$ is associated with the melting point, supported by visual observation. The endothermic peak between 50 and $100^{\circ} \mathrm{C}$ is not related to the melting point, and may be caused by a phase transition or by water evaporation, but further experiments may be performed to clarify this issue. 

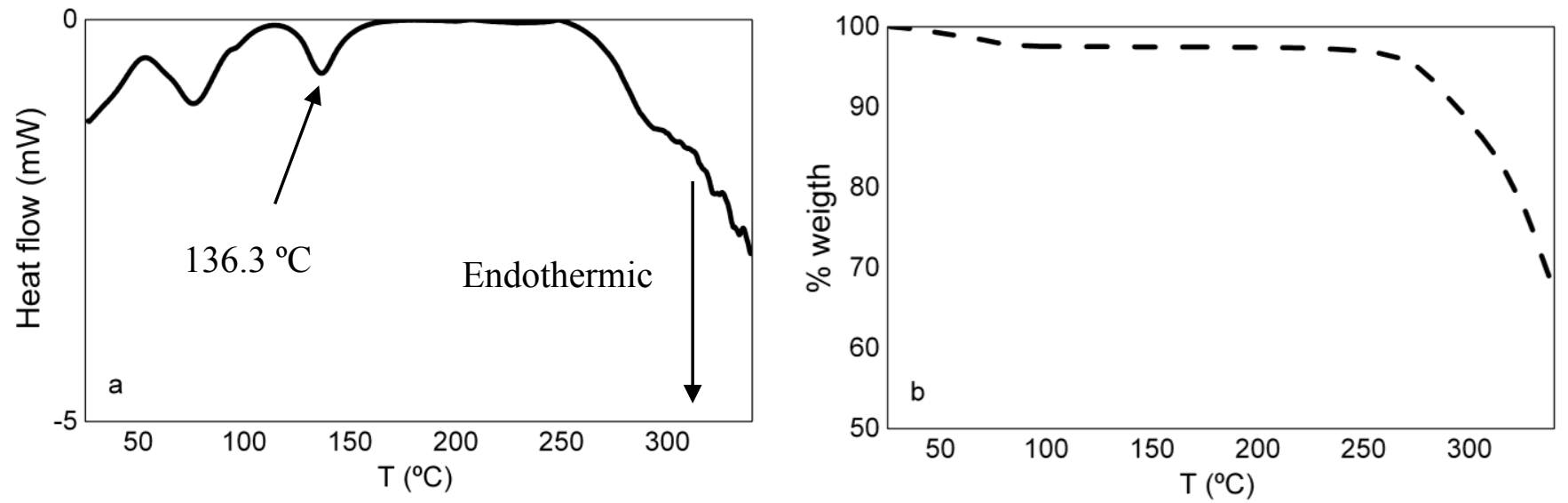

Figure S5. a) DSC and b) TG of $\left[\mathrm{BMIm}^{+}\right]\left[\mathrm{HPTS}^{-3}\right]$.

\section{References}

[1] J. B. Birks, Photophysics of aromatic molecules, John Wiley \& Sons Ltd, London 1970.

[2] Kossert, K. Activity Standardization by Means of a New TDCR-Čerenkov Counting Technique. Appl. Radiat. Isot. 2010, 68, 1116-1120.

[3] Efimova, A.; Hubrig, G.; Schmidt, P. Thermal Stability and Crystallization Behavior of Imidazolium Halide Ionic Liquids. Thermochim. Acta 2013, 573, 162-169.

[4] Strechan, A. A. ; Paulechka, Y. U. ; Kabo, A. G. ; Blokhin, A. V. ; Kabo, G. J. 1-Butyl-3methylimidazolium Tosylate Ionic Liquid: Heat Capacity, Thermal Stability, and Phase Equilibrium of Its Binary Mixtures with Water and Caprolactam. J. Chem. Eng. Data 2007, 52, 1791-1799. 